\title{
THERMAL CIRCUIT CALCULATION AND REAL-TIME ANALYSIS OF LED LIGHT SOURCE LUMINAIRES
}

\begin{abstract}
Bircan YÜKSEL ${ }^{1^{*}}$, İsmail KIYAK ${ }^{2}$
In semiconductor luminaires, thermal circuit design is important since operating temperature directly affects performance and life of luminaires. In this study; In order to keep operating temperature of LED light source luminaires normal, thermal circuit is emphasized. In this context, necessary information about LED and thermal resistance calculation are given in this study. As a real-time application, 10 different power luminaires have been determined on market, thermal resistance calculations have been made depending on heat that needs to be removed and required area calculations have been made for heatsink that needs to be used. Comparative analysis of thermal circuit area calculation results were made with existing heatsink areas of luminaires. Accordingly, it was concluded that thermal circuit designed luminaires which has insufficient heat sink area have a shorter life of approximately $22.7 \%$ compared to others.
\end{abstract}

Key words: LED; Thermal resistance; Junction Temperature; heatsink area

\section{Introduction}

Artificial lighting, which constitutes about $19 \%$ of the world's electricity consumption, started with the discovery of electromagnetism and electric current. As a result, cheap and simple structured lighting sources were tried to be designed. First, incandescent bulbs were found. Electric current was passed through a filament lamp wire and light was obtained [1]. Incandescent bulbs have disadvantages such as short life and low light efficiency. For this reason, halogen lamps, high intensity discharge lamps, fluorescent lamps, which are more efficient light sources than incandescent bulbs, was preferred in lighting.These sources have also led solid state lighting studies, which are more efficient and environmentally friendly due to their low lumen depreciation and mercury content [2-4].

LEDs, which are solid state lighting sources, were first obtained in 1962 in red color with a efficiency of $0.1 \mathrm{~lm} / \mathrm{W}$ [5]. At first, it was used in calculators, signage, brake lights, digital clocks and test equipment [6]. Thanks to the recently developed LED and LED technology, it is widely used in lighting. Considering the amount of electricity consumption, it has higher illumination than other lighting sources [7]. It provide long life, reliability and energy savings compared to traditional lighting [8].

\footnotetext{
${ }^{1}$ Institute of Pure and Applied Science, Marmara University, Kadiköy, Istanbul, Turkey, (bircanyukse198@gmail.com) https://orcid.org/0000-0002-0572-2884

2 Faculty of Technology, Department of Electrical and Electronics, Marmara University, Kadiköy, Istanbul, Turkey, (imkiyak@marmara.edu.tr) (D) https://orcid.org/0000-0002-5061-6378
} 
Operation principle of LEDs is based on an event called electroluminescence [9]. In its simplest sense, an LED is a combination of $\mathrm{p}$ and $\mathrm{n}$ type two semiconductor materials. Under forward bias condition electrons in n-type region move from junction region to p-type region. During transition, electron hole produces photons in infrared or visible light spectrum. Energy occurs when electron hole pair emits photon. Approximately 20\% to 25\% of energy output is light and the rest is heat. Wavelength and color of light are determined by differences in energy levels of electrons and holes [5,10,11].

As most of energy output is converted to heat, LED performance will be affected and its reliability will be shaken. Reliability problem which affect lighting quality and life of LED system is an important factor. LED systems contain two main components: optics and drivers. The driver is the weakest component in LED lamp [12]. Increasing temperature of LED driver will decrease its lifetime. For this reason, the operating temperature of an LED driver should be maximum $75^{\circ} \mathrm{C}-85^{\circ} \mathrm{C}$ [13].

Increase in temperature has also a significant impact on performance and cost. The efficiency of LED $(1 \mathrm{~m} / \mathrm{W})$ decreases when junction region temperature increases. When efficiency decreases, illumination intensity also decreases. Therefore, LED number and power in luminaire should be increased This causes cost to increase. The temperature may cause a decrease in CRI (color rendering index) of luminaire, an increase in dominant wavelength of luminaire and color temperature of light output. Dominant wavelength means reduced probability of reproducing true colors [14].

In this study, two different thermal resistance calculation methods were emphasized to investigate effect of LED operating temperature on its lifetime. For real-time luminaires with different powers, resistance and cooling area were calculated. Technical data was taken into consideration. In second of this study, semiconductor thermal circuit of LED is mentioned, and thermal resistance calculation methods are mentioned in third part. In fourth part, thermal resistances and cooler areas were calculated for different powers of real-time luminaire, and a comparative analysis of luminaires is made according to results of calculations.

\section{Thermal Resistance for Semiconductors}

Thermal resistance is defined as rate of temperature increase for given power and it is also known as ability to dissipate heat [15].

A typical LED package consists of an LED chip, epoxy resins, a heat slug, and a heat sink. The heat generated in the LED chip is distributed in three ways: transmission, convection and radiation [16]. Transmission is dissipation process that occurs as dominant on an LED chip or packet. Convection is the transfer of generated heat in LED from heat sink to ambient air in LED system. Radiation occurs when it leaves surface through electromagnetic waves and moves until another surface is encountered. Radiation heat transfer can be neglected when very low values are obtained compared to convection and conduction [15].Figure 1 shows thermal resistance circuit of LED and flow direction of heat.

The purpose of LED thermal circuit is obtain low thermal resistance. After LED chip comes PCB part and it consists of upper part which is circuit layer, middle part which is dielectric layer, thin copper layer or third part which is thick metal layer. Metal core PCB (MPCB) or FR-4 PCB are most commonly used PCB materials according to heat dissipation requirementFR-4 is used in low power LED applications and MPCB is used in medium power applications [17]. 


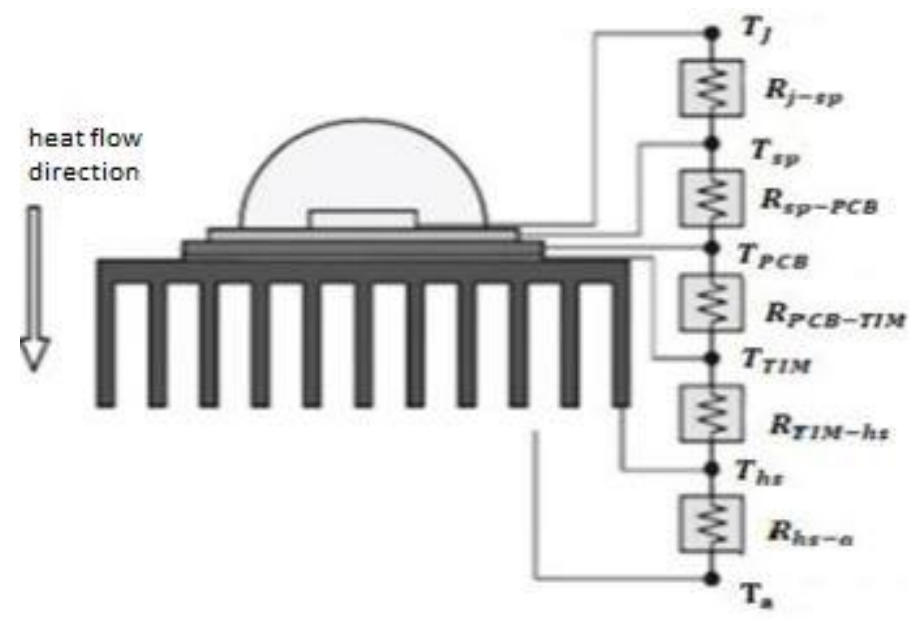

Figure 1. Thermal Resistance circuit of a LED [15]

Main thermal objective in packaging of LED is transfer heat efficiently from LED chip to environment. Contact surfaces between package and heatsink are somewhat incompatible and rough. Heat transfer between package and heat sink occurs via micro contacts of surfaces and air-filled micro gaps. This causes significant thermal resistance.
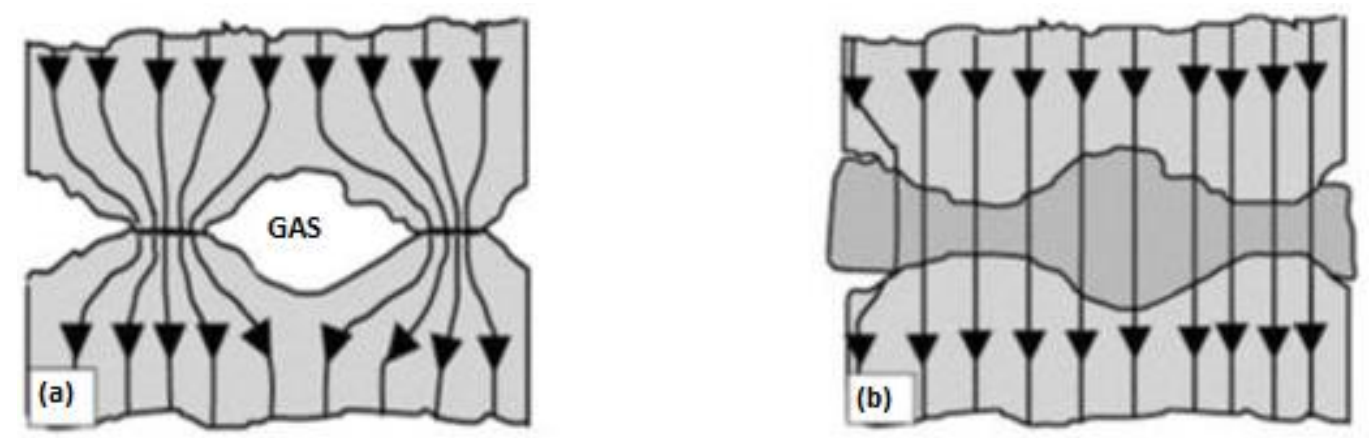

Figure 2. (a) Heat flow in directly contact (b) heat flow separated by a thermal interface material [18]

As shown in Figure 2, thermal interface materials (TIM) with a high thermal conductivity are generally used to reduce thermal contact resistance between package and heat sink. Interface materials used should not be thicker than $0,3 \mathrm{~mm}$. If it is thicker it causes an increase in resistance [18].

\section{Thermal Resistance Calculation Methods}

When a voltage is applied to LED, current passes over semiconductor material and heat is created on LED under effect of this current. General formula of thermal resistance that will occur as a result of current passing is shown in $\mathrm{Eq}(1)$.

$$
R_{a-b}=\frac{T_{a}-T_{b}}{P_{t h}}
$$

\subsection{Resistance Calculation with Conventional Method}

Thermal surface calculation formulas are calculated with the help of Equation 2-5 when heat sink channels are designed horizontally on ground: 


$$
\begin{gathered}
P_{d}=P_{t h} *(\text { efficiency }) \\
T_{s p}=T_{j}-\left(R_{j-s p} * P_{d}\right) \\
T_{h s}=T_{s p}-\left(R_{s p-h s} * P_{d}\right) \\
R_{h s-a}=\frac{T_{h s}-T_{a}}{P_{t h}}
\end{gathered}
$$

$P_{d}$ is amount of heat that must be cooled as a result of power consumed by LED. If an insulating material is used between LED and heat sink, value of $R_{s p-h s}$ should be chosen between 0,2 and 0,5.

According to result obtained from eq. 5, required surface area for horizontal heat sink channels is calculated based on graphic in figure 3.

If heat sink channels are designed vertical to ground, horizontal surface wideness is calculated as follows $\left(\mathrm{S}_{\mathrm{y}}\right)$ :

$$
S_{y}=\sqrt{P_{d} * 10}
$$

In order to calculate required heat sink area per total watt of luminaire, surface areas calculated for both horizontal and vertical design must be collected.

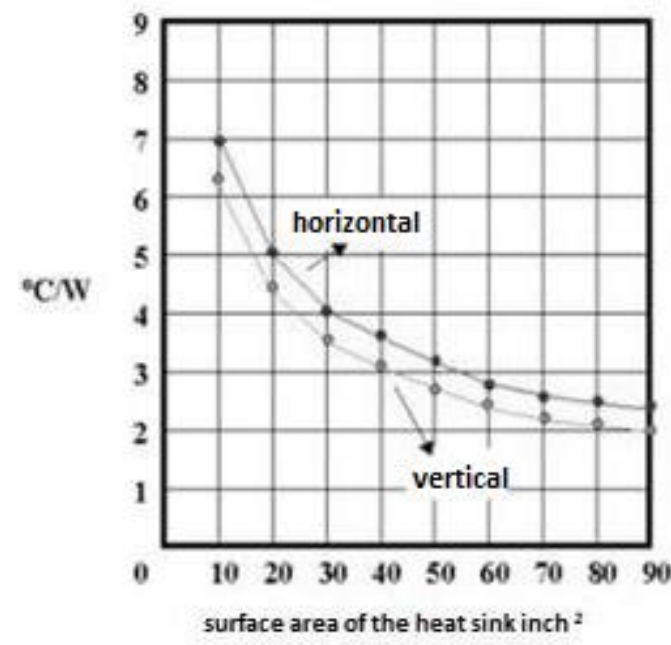

Figure 3. Heat Sink Area- Thermal Conduction [20]

Material used as heat sink was chosen as aluminum because it is cheap and easy to process [19]. Figure 3 is heat sink area-thermal conduction graph of aluminum [20].

\subsection{Resistance Calculation with Convection Method}

Another resistance calculation method is resistance calculation method obtained from convection heat dissipation. It is calculated with the help of Equations 7-11.

$$
\begin{aligned}
& R_{t h}=\frac{1}{h A} \\
& h=\frac{N u \lambda}{l}
\end{aligned}
$$




$$
\begin{aligned}
N u & =0,59 \sqrt[4]{G r * P r} \\
G r & =\frac{g \beta\left(T_{h s}-T_{a}\right) l^{3}}{v^{2}} \\
\beta & =\frac{1}{\frac{T_{h s}+T_{a}}{2}}
\end{aligned}
$$

Calculation with convection resistance method is more common than these two resistance calculation methods.

\section{Applications of Real Time Luminaires}

Thermal resistance and heat sink area calculation were made by using two thermal resistance calculation methods for ten luminaires with different powers. Electrical and thermal properties of luminaires used for calculation were obtained from the manufacturer. Table 1 shows real time data of

\begin{tabular}{|c|c|c|c|c|c|c|c|c|}
\hline Luminaire Name & $\begin{array}{l}\text { Operating } \\
\text { Voltage } \\
\text { (V) }\end{array}$ & $\begin{array}{l}\text { Operating } \\
\text { Current } \\
\text { (A) }\end{array}$ & $\begin{array}{l}\text { Power } \\
\text { (W) }\end{array}$ & $\begin{array}{l}\text { Luminous } \\
\text { flux (lm) }\end{array}$ & $\begin{array}{l}\text { Power } \\
\text { Factor }\end{array}$ & $\begin{array}{l}\text { Thermal } \\
\text { circuit } \\
\text { resistance } \\
\left({ }^{\circ} \mathrm{C} / \mathbf{W}\right)\end{array}$ & $\begin{array}{l}\text { Heat sink } \\
\text { thickness } \\
(\mathrm{mm})\end{array}$ & $\begin{array}{l}\text { Heat sink } \\
\text { area }\left(\mathrm{cm}^{2}\right)\end{array}$ \\
\hline Luminaire 1 & 24 & 500 & 14 & 300 & 0,7 & 5,164 & 44 & 207,165 \\
\hline Luminaire 2 & 24 & 650 & 15 & 500 & 0,7 & 4,75 & 54 & 233,779 \\
\hline Luminaire 3 & 24 & 720 & 18 & 750 & 0,7 & 3,873 & 56 & 285,307 \\
\hline Luminaire 4 & 24 & 800 & 20 & 1500 & 0,8 & 2,902 & 61 & 374,782 \\
\hline Luminaire 5 & 25 & 850 & 24 & 2000 & 0,8 & 2,354 & 28,5 & 381,723 \\
\hline Luminaire 6 & 25 & 920 & 25 & 2200 & 0,8 & 2,252 & 45 & 420,924 \\
\hline Luminaire 7 & 32 & 980 & 27 & 2500 & 0,9 & 1,793 & 24 & 454,541 \\
\hline Luminaire 8 & 32 & 1000 & 29 & 3000 & 0,9 & 1,638 & 27 & 505,324 \\
\hline Luminaire 9 & 50 & 1050 & 45 & 4000 & 0,9 & 0,978 & 3,8 & 518,948 \\
\hline Luminaire10 & 50 & 1200 & 48 & 4500 & 0,9 & 0,904 & 3,7 & 550,709 \\
\hline
\end{tabular}
luminaires.

Table 1. Real time data of luminaires

\subsection{Resistance Calculations with Conventional Method}

Solder point temperature $\left(T_{s p}\right)$ value was taken as $85^{\circ} \mathrm{C}$ and ambient temperature $\left(T_{a}\right)$ value as $40{ }^{\circ} \mathrm{C}$ in calculations conventional method calculations. Thickness value $\left(R_{s p-h s}\right)$ between solder point and the heat sink was taken 0,2 and the results were obtained. An example calculation with conventional method for luminaire 1 is shown below. Analysis results for other luminaires are given in Table 2.

Power of luminaire 1 is $14 \mathrm{~W}$ and its efficiency is 0,7

$$
\begin{gathered}
P_{d}=14 * 0,7=9,8 \mathrm{~W} \\
T_{h s}=85-(0,2 * 9,8)=83,04^{\circ} \mathrm{C}
\end{gathered}
$$




$$
R_{h s-a}=\frac{83,04-40}{9,8}=4,39^{\circ} \mathrm{C} / \mathrm{W}
$$

Horizontal Heat Sink Channel Surface Area:

$$
249,037 \mathrm{~cm}^{2}
$$

Vertical Heat Sink Channel Surface Area:

$$
\sqrt{9,8 * 10}=9,89 \mathrm{~cm}^{2}
$$

Total heat sink area of luminaire 1:

\begin{tabular}{|c|c|c|c|c|c|c|}
\hline Luminaire Name & $\left(\boldsymbol{P}_{d}\right)(\mathbf{W})$ & $\begin{array}{l}\text { Heat sink } \\
\text { temperature } \\
\left(T_{h s}\right)\left({ }^{\circ} \mathrm{C}\right)\end{array}$ & $\begin{array}{l}\text { Thermal } \\
\text { Resistance } \\
\left(\boldsymbol{R}_{h s-a}\right)\left({ }^{\circ} \mathrm{C} /\right. \\
\text { W })\end{array}$ & $\begin{array}{l}\text { Horizontal Heat } \\
\text { Sink Channel } \\
\text { Surface Area } \\
\left(\mathrm{cm}^{2}\right)\end{array}$ & $\begin{array}{l}\text { Vertical Heat } \\
\text { Sink Surface } \\
\text { Area }\left(\mathrm{cm}^{2}\right)\end{array}$ & $\begin{array}{l}\text { Total Heat Sink } \\
\text { Area of } \\
\text { uminaire } \\
\left(\mathrm{cm}^{2}\right)\end{array}$ \\
\hline Luminaire 1 & 9,8 & 83,04 & 4,39 & 249,037 & 9,89 & 258,957 \\
\hline Luminaire 2 & 10,5 & 82,9 & 4,085 & 267,958 & 10,24 & 278,198 \\
\hline Luminaire 3 & 12,6 & 82,48 & 3,37 & 325,413 & 11,22 & 336,663 \\
\hline Luminaire 4 & 16 & 81,8 & 2,612 & 390,957 & 12,64 & 431,197 \\
\hline Luminaire 5 & 19,2 & 81,16 & 2,143 & 425,126 & 13,856 & 438,982 \\
\hline Luminaire 6 & 20 & 81 & 2,05 & 465,712 & 14,142 & 479,854 \\
\hline Luminaire 7 & 24,3 & 80,14 & 1,65 & 502,589 & 15,588 & 518,177 \\
\hline Luminaire 8 & 26,1 & 79,78 & 1,524 & 539,702 & 16,155 & 555,857 \\
\hline Luminaire 9 & 40,5 & 76,9 & 0,91 & 550,727 & 20,12 & 570,843 \\
\hline Luminaire 10 & 43,2 & 76,36 & 0,841 & 585,170 & 20,78 & 605,78 \\
\hline
\end{tabular}

$$
249,037+9,89=258,927 \mathrm{~cm}^{2}
$$

Table 2. Thermal analysis results with conventional method

\subsection{Resistance Calculations with Convection Method}

Solder point temperature $\left(T_{s p}\right)$ value was taken as $85^{\circ} \mathrm{C}$ and ambient temperature $\left(T_{a}\right)$ value as $40^{\circ} \mathrm{C}$ in calculations convection method calculations. Thermal conductivity $(\lambda)$ of air at $40{ }^{\circ} \mathrm{C}$ is $0,2662 \mathrm{~W} / \mathrm{mK}$, kinematic viscosity value of air $(v) 1,702 \cdot 10^{-5}$, Prandtl number for air was taken as 0,7255 , heat sink thickness was selected for characteristic length value of $l$. An example calculation with convection method for luminaire 1 is shown below. Analysis results for other luminaires are given in Table 3.

Power of luminaire 1 is $14 \mathrm{~W}$ and its thickness is $2,7 \mathrm{~mm}$

$$
\beta=\frac{2}{85+40}=0,016
$$




$$
\begin{gathered}
G r=\frac{9,81 * 0,016 * 45 *(0,0027)^{3}}{\left(1,702 * 10^{-5}\right)^{10}}=2531488,543 \\
N u=0.59 \sqrt[4]{(2531488,543 * 0.7255)}=21,719 \\
h=\frac{21,719 \times 0,2662}{0,0027}=12,603 \\
R_{t h}=\frac{1}{12,603 \times 191,82 \times 10^{-4}}=4,252
\end{gathered}
$$

\begin{tabular}{|c|c|c|c|c|c|c|c|}
\hline $\begin{array}{l}\text { Luminaire } \\
\text { Name }\end{array}$ & $\begin{array}{l}\text { Heat Sink } \\
\text { Thickness } \\
(\mathrm{mm})\end{array}$ & $\beta$ & $\begin{array}{l}\text { Groshof number } \\
(\boldsymbol{G r})\end{array}$ & $\begin{array}{l}\text { Nusselt } \\
\text { number } \\
(\mathrm{Nu})\end{array}$ & $\begin{array}{l}\text { Heat } \\
\text { transfer } \\
\text { coefficient } \\
\left(W / m^{2} K\right)\end{array}$ & $\begin{array}{l}\text { Thermal } \\
\text { Resistance } \\
\left(R_{h s-a}\right) \\
\left({ }^{\circ} \mathbf{C} / \mathbf{W}\right)\end{array}$ & $\begin{array}{l}\text { Total Heat } \\
\text { Sink Area of } \\
\text { Luminaire } \\
\left(\mathrm{cm}^{2}\right)\end{array}$ \\
\hline Luminaire 1 & 44 & 0,016 & 2077018,772 & 20,671 & 12,46 & 3,873 & 300,389 \\
\hline Luminaire 2 & 54 & 0,016 & 3839402,751 & 24,1 & 11,849 & 3,61 & 336,641 \\
\hline Luminaire 3 & 56 & 0,016 & 4281998,13 & 24,769 & 11,753 & 2,982 & 407,989 \\
\hline Luminaire 4 & 61 & 0,016 & 5534417,238 & 26,41 & 11,495 & 2,321 & 524,694 \\
\hline Luminaire 5 & 28,5 & 0,016 & 564438,946 & 14,925 & 14,925 & 1,883 & 530,594 \\
\hline Luminaire 6 & 45 & 0,016 & 2219611,682 & 21,017 & 12,412 & 1,914 & 580,875 \\
\hline Luminaire 7 & 24 & 0,016 & 337066,908 & 13,120 & 14,435 & 1,524 & 613,63 \\
\hline Luminaire 8 & 27 & 0,016 & 479925,343 & 4,331 & 14,054 & 1,408 & 667,027 \\
\hline Luminaire 9 & 3,8 & 0,016 & 1337,929 & 3,293 & 22,912 & 0,841 & 674,596 \\
\hline Luminaire10 & 3,7 & 0,016 & 1235,058 & 3,227 & 23,102 & 0,786 & 699,4 \\
\hline
\end{tabular}

Table 3. Thermal analysis results with convection method

\section{Conclusions}

In study, resistance and cooling calculate were made by conventional and conventional methods for 10 different luminaires. For heat sink area of first luminaire, calculation results obtained by conventional method and convection method were found $258,957 \mathrm{~cm}^{2}$ and $300,389 \mathrm{~cm}^{2}$, respectively. The results show that heat sink area obtained by conventional method is $20 \%$ larger than heat sink area of first luminaire, and heat sink area obtained by convention method is $45 \%$ larger. For heat sink area of second luminaire, calculation results obtained by conventional method and convection method were found $278,198 \mathrm{~cm}^{2}$ and $336,641 \mathrm{~cm}^{2}$, respectively. The results show that heat sink area obtained by conventional method is $19 \%$ larger than heat sink area of second luminaire, and heat sink area obtained by convention method is $44 \%$ larger. For heat sink area of third luminaire, calculation results obtained by conventional method and convection method were found $336,663 \mathrm{~cm}^{2}$ and $407,989 \mathrm{~cm}^{2}$, respectively. The results show that heat sink area obtained by conventional method is $18 \%$ larger than heat sink area of third luminaire, and heat sink area obtained by convention method is $43 \%$ larger. For heat sink area of fourth luminaire, calculation results obtained by conventional method and convection 
method were found $431,197 \mathrm{~cm}^{2}$ and $524,694 \mathrm{~cm}^{2}$, respectively. The results show that heat sink area obtained by conventional method is $15 \%$ larger than heat sink area of fourth luminaire, and heat sink area obtained by convention method is $40 \%$ larger. For heat sink area of fifth luminaire, calculation results obtained by conventional method and convection method were found 438,982 $\mathrm{cm}^{2}$ and $530,594 \mathrm{~cm}^{2}$, respectively. The results show that heat sink area obtained by conventional method is $15 \%$ larger than heat sink area of fifth luminaire, and heat sink area obtained by convention method is $39 \%$ larger.For heat sink area of sixth luminaire, calculation results obtained by conventional method and convection method were found $479,854 \mathrm{~cm}^{2}$ and $580,875 \mathrm{~cm}^{2}$, respectively. The results show that heat sink area obtained by conventional method is $14 \%$ larger than heat sink area of sixth luminaire, and heat sink area obtained by convention method is $38 \%$ larger.For heat sink area of seventh luminaire, calculation results obtained by conventional method and convection method were found $518,177 \mathrm{~cm}^{2}$ and $613,63 \mathrm{~cm}^{2}$, respectively. The results show that heat sink area obtained by conventional method is $14 \%$ larger than heat sink area of seventh luminaire, and heat sink area obtained by convention method is $35 \%$ larger.For heat sink area of eighth luminaire, calculation results obtained by conventional method and convection method were found $555,857 \mathrm{~cm}^{2}$ and $667,027 \mathrm{~cm}^{2}$, respectively. The results show that heat sink area obtained by conventional method is $10 \%$ larger than heat sink area of eighth luminaire, and heat sink area obtained by convention method is $32 \%$ larger. For heat sink area of ninth luminaire, calculation results obtained by conventional method and convection method were found $570,843 \mathrm{~cm}^{2}$ and $674,596 \mathrm{~cm}^{2}$, respectively. The results show that heat sink area obtained by conventional method is $10 \%$ larger than heat sink area of ninth luminaire, and heat sink area obtained by convention method is $30 \%$ larger. For heat sink area of tenth luminaire, calculation results obtained by conventional method and convection method were found $605,78 \mathrm{~cm}^{2}$ and $699,4 \mathrm{~cm}^{2}$, respectively. The results show that heat sink area obtained by conventional method is $10 \%$ larger than heat sink area of tenth luminaire, and heat sink area obtained by convention method is $27 \%$ larger. Results of comparison are given graphically in Figure 4.

Minimazing of heat sink area will negatively affect deterioration constant (e) (approximately 22.7) according to T21 method, which is one of LED life tests performed for 1000 hours , LED chip life will be shortened negatively at similar rates. Within scope of reducing cost of heat sink circuit of the companies, it is observed that there are differences in the ratio of heat sink areas of products produced with actual heat sink area depending on method. Similarly, there are differences in calculation of thermal circuit resistance. As a dependent on calculated resistance, it will change in area that needs to be cooled. Therefore, resistance calculation must be done correctly. When calculations are investigated, resistance value of first luminaire obtained as a result of resistance calculation by conventional method is $4,39^{\circ} \mathrm{C} / \mathrm{W}$ and resistance value obtained by convection method is $3,873^{\circ} \mathrm{C} / \mathrm{W}$. When the resistance value obtained from the technical data is compared with the resistance value obtained by the conventional method, the resistance value calculated is approximately $15 \%$ smaller, and compared to the resistance value obtained by the convection method, the resistance value is approximately $25 \%$ smaller. 


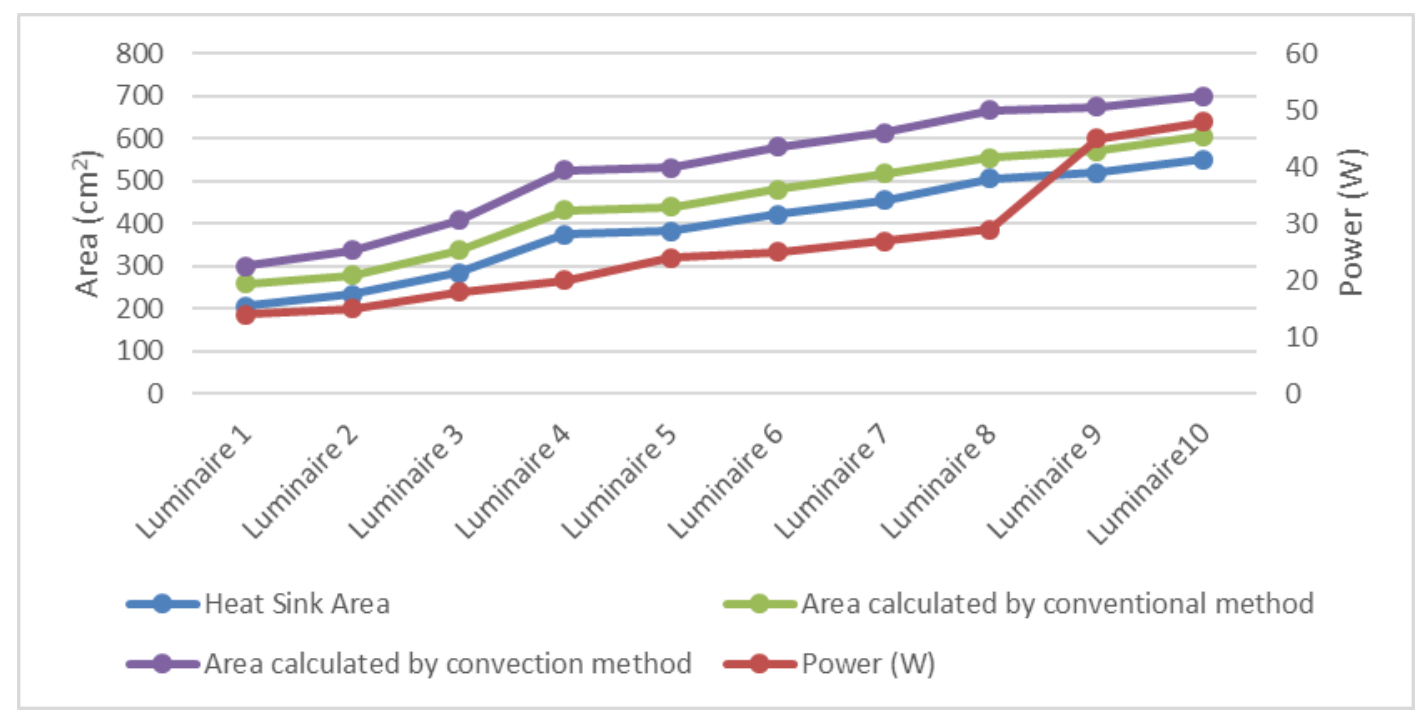

Figure 4. Comparison graph of power and heat sink surface areas of different luminaires

Resistance value of second luminaire obtained as a result of resistance calculation by conventional method is $4,085^{\circ} \mathrm{C} / \mathrm{W}$ and resistance value obtained by convection method is $3,61^{\circ} \mathrm{C} / \mathrm{W}$. When the resistance value obtained from the technical data is compared with the resistance value obtained by the conventional method, the resistance value calculated is approximately $14 \%$ smaller, and compared to the resistance value obtained by the convection method, the resistance value is approximately $24 \%$ smaller. Resistance value of third luminaire obtained as a result of resistance calculation by conventional method is $3,37^{\circ} \mathrm{C} / \mathrm{W}$ and resistance value obtained by convection method is $2,982^{\circ} \mathrm{C} / \mathrm{W}$. When the resistance value obtained from the technical data is compared with the resistance value obtained by the conventional method, the resistance value calculated is approximately $13 \%$ smaller, and compared to the resistance value obtained by the convection method, the resistance value is approximately $23 \%$ smaller. Resistance value of fourth luminaire obtained as a result of resistance calculation by conventional method is $2,612^{\circ} \mathrm{C} / \mathrm{W}$ and resistance value obtained by convection method is $2,321^{\circ} \mathrm{C} / \mathrm{W}$. When the resistance value obtained from the technical data is compared with the resistance value obtained by the conventional method, the resistance value calculated is approximately $10 \%$ smaller, and compared to the resistance value obtained by the convection method, the resistance value is approximately $20 \%$ smaller. Resistance value of fifth luminaire obtained as a result of resistance calculation by conventional method is $2,143^{\circ} \mathrm{C} / \mathrm{W}$ and resistance value obtained by convection method is $1,883^{\circ} \mathrm{C} / \mathrm{W}$. When the resistance value obtained from the technical data is compared with the resistance value obtained by the conventional method, the resistance value calculated is approximately 9\% smaller, and compared to the resistance value obtained by the convection method, the resistance value is approximately $20 \%$ smaller. Resistance value of sixth luminaire obtained as a result of resistance calculation by conventional method is $2,05^{\circ} \mathrm{C} / \mathrm{W}$ and resistance value obtained by convection method is $1,914^{\circ} \mathrm{C} / \mathrm{W}$. When the resistance value obtained from the technical data is compared with the resistance value obtained by the conventional method, the resistance value calculated is approximately 9\% smaller, and compared to the resistance value obtained by the convection method, the resistance value is approximately $15 \%$ smaller. Resistance value of seventh luminaire obtained as a result of resistance calculation by conventional method is $1,65^{\circ} \mathrm{C} / \mathrm{W}$ and resistance value obtained by convection method is $1,524^{\circ} \mathrm{C} / \mathrm{W}$. When the resistance value obtained from the technical data is compared with the resistance value obtained by the conventional method, the resistance value calculated is approximately 
$8 \%$ smaller, and compared to the resistance value obtained by the convection method, the resistance value is approximately $15 \%$ smaller. Resistance value of eighth luminaire obtained as a result of resistance calculation by conventional method is $1,524^{\circ} \mathrm{C} / \mathrm{W}$ and resistance value obtained by convection method is $1,408^{\circ} \mathrm{C} / \mathrm{W}$. When the resistance value obtained from the technical data is compared with the resistance value obtained by the conventional method, the resistance value calculated is approximately $7 \%$ smaller, and compared to the resistance value obtained by the convection method, the resistance value is approximately $14 \%$ smaller. Resistance value of ninth luminaire obtained as a result of resistance calculation by conventional method is $0,91^{\circ} \mathrm{C} / \mathrm{W}$ and resistance value obtained by convection method is $0,841^{\circ} \mathrm{C} / \mathrm{W}$. When the resistance value obtained from the technical data is compared with the resistance value obtained by the conventional method, the resistance value calculated is approximately $7 \%$ smaller, and compared to the resistance value obtained by the convection method, the resistance value is approximately $14 \%$ smaller. Resistance value of tenth luminaire obtained as a result of resistance calculation by conventional method is $0,841^{\circ} \mathrm{C} / \mathrm{W}$ and resistance value obtained by convection method is $0,786^{\circ} \mathrm{C} / \mathrm{W}$. When the resistance value obtained from the technical data is compared with the resistance value obtained by the conventional method, the resistance value calculated is approximately $7 \%$ smaller, and compared to the resistance value obtained by the convection method, the resistance value is approximately $13 \%$ smaller. As a result of analysis methods, it is observed that conventional method is not sufficient for a detailed calculation, but convection method contains detailed calculations. Results of comparison are given graphically in Figure 5.

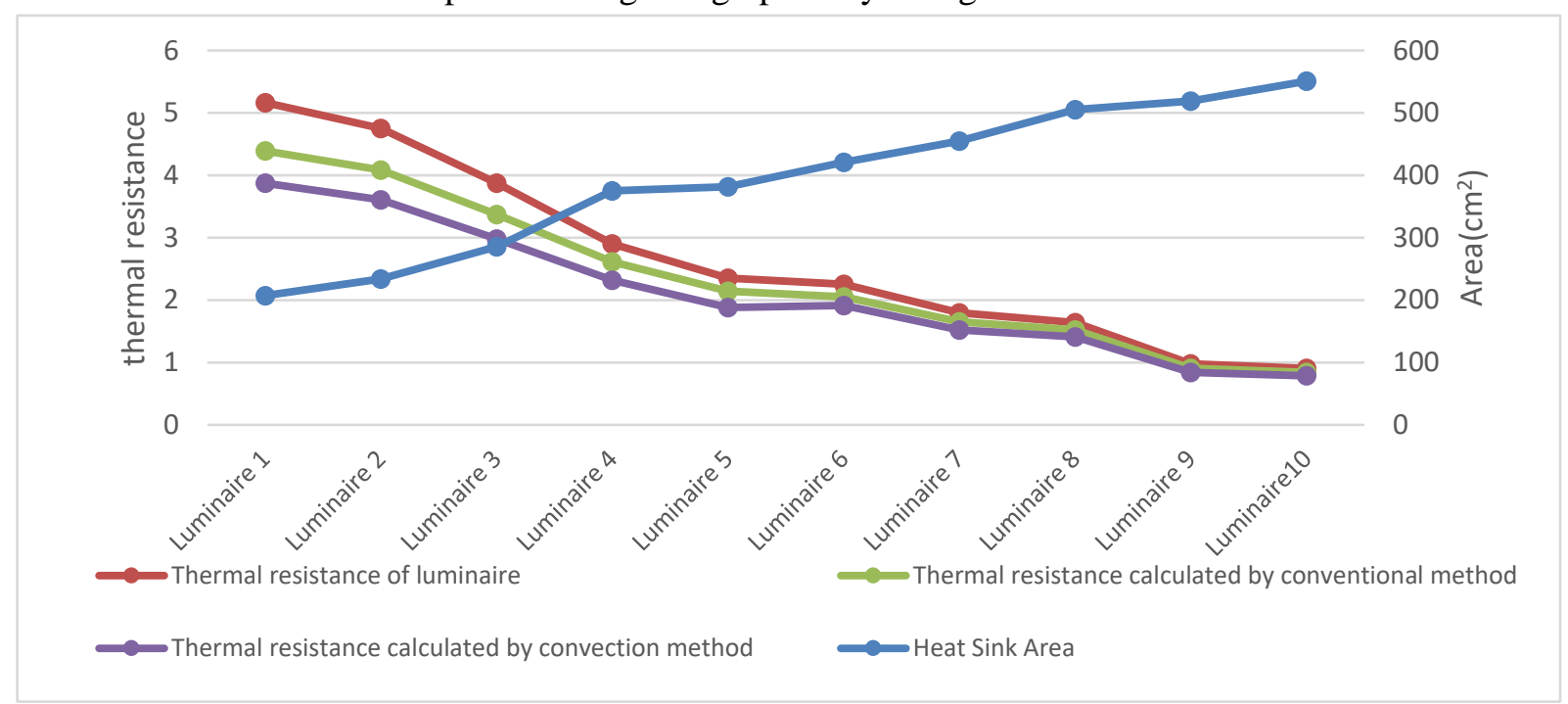

Figure 5. Comparison graph of thermal circuit resistance and heat surface areas of different luminaire

As a result, it is observed that thermal resistance decreases due to increase in power, but area required for heatsink increases. It was concluded that luminaire group with powers of $14 \mathrm{~W}, 15 \mathrm{~W}, 18 \mathrm{~W}$ was bad, luminaire group with powers of $20 \mathrm{~W}, 24 \mathrm{~W}, 25 \mathrm{~W}$ was medium, luminaire group with powers of $27 \mathrm{~W}$, $29 \mathrm{~W}, 45 \mathrm{~W}$ and 48W was good thermal analysis values. As a result of analysis methods, it is observed that conventional method is not sufficient for a detailed calculation, but convection method contains detailed calculations. While only temperature and power are used in conventional method calculations, many factors such as viscosity of air, which changes depending on temperature that will affect resistance, gravity acceleration and heat transmission coefficient are used in calculations of convection method. Temperature is very important for LED. If temperature in LED cannot be removed correctly, 
heat generated will affect performance of LED. As a result, consumers will lose confidence in the product. Therefore, thermal management should be given importance in LED designs, thermal resistance value should be calculated correctly and heat sink design must be done well. Using the convection method for thermal calculations of LED will provide more reliable results.

\begin{tabular}{|c|c|c|c|}
\hline $\begin{array}{l}\text { Abbreviation } \\
\text { List }\end{array}$ & Explanations & $\begin{array}{l}\text { Abbreviation } \\
\text { List }\end{array}$ & Explanations \\
\hline$R_{a-b}$ & $\begin{array}{l}\text { the thermal resistance from point } \\
\text { "a" to point "b" }\left({ }^{\circ} \mathrm{C} / \mathrm{W}\right)\end{array}$ & $\boldsymbol{D}$ & Kinematic viscosity of air \\
\hline$P_{\text {th }}$ & the thermal power $(\mathrm{W})$ & $R_{\text {f }-s p}$ & $\begin{array}{l}\text { Junction to solder point thermal } \\
\text { resistance }\end{array}$ \\
\hline$T_{\propto}$ & the temperature at point "a" $\left({ }^{\circ} \mathrm{C}\right)$ & $R_{g p-P C D}$ & $\begin{array}{l}\text { Solder point to printed circuit } \\
\text { board resistance }\end{array}$ \\
\hline$T_{b}$ & the temperature at point " $\mathrm{b}$ " $\left({ }^{\circ} \mathrm{C}\right)$ & $R_{P G B-T M}$ & $\begin{array}{l}\text { Printed circuit board to thermal } \\
\text { interface material resistance }\end{array}$ \\
\hline$A$ & Heatsink area $\left(\mathrm{m}^{2}\right)$ & $R_{\text {THM-hs }}$ & $\begin{array}{l}\text { Thermal interface material to } \\
\text { heat sink resistance }\end{array}$ \\
\hline$h$ & $\begin{array}{l}\text { Heat transfer coefficient of the } \\
\text { surface }\left(\mathrm{W} / \mathrm{m}^{2} \mathrm{~K}\right)\end{array}$ & $R_{h g-a}$ & Heat sink to ambient resistance \\
\hline Nu & Nusselt number & $T_{\mathbb{T}}$ & Junction temperature $\left({ }^{\circ} \mathrm{C}\right)$ \\
\hline$\lambda$ & Thermal conductivity of air & $T_{s p}$ & Solder point temperature $\left({ }^{\circ} \mathrm{C}\right)$ \\
\hline l & Characteristic length & $T_{p \in D}$ & $\begin{array}{l}\text { Printed circuit board } \\
\text { temperature }\end{array}$ \\
\hline$G r$ & Grashof number & $T_{\text {THM }}$ & $\begin{array}{l}\text { Thermal interface material } \\
\text { temperature }\end{array}$ \\
\hline $\operatorname{Pr}$ & Prandtl number & $T_{\text {hs }}$ & Heat sink temperature \\
\hline$g$ & Acceleration of gravity & $T_{a}$ & Ambient temperature \\
\hline
\end{tabular}

\section{REFERANS}

[1] Chitnis, D., Thejo kalyani, N. , Swart, H., Dhoble, S., Escalating opportunities in the field of lighting, Renewable and Sustainable Energy Reviews, 64 (2016), pp. 727-748.

[2] Nardelli, A., Deuschle, E., de Azevedo, L. D., Pessoa, J. L. N., Ghisi, E., Assessment of Light Emitting Diodes technology for general lighting: A critical review, Renewable and Sustainable Energy Reviews,75,2017, pp.368-379.

[3]***, United Nations Environment Programme. Assessment of opportunities for global harmonization of minimum energy performance standards and test standards for lighting products. Collaborative Labelling and Appliance Standards Program.

[4] Khan,N., Abas, N., Comparative study of energy saving light sources, Renewable and Sustainable Energy Reviews, 15 (2011), 1, pp. 296-309.

[5] Yam, F., Hassan, Z., Innovative advances in LED technology,Microelectronics Journal,36 (2005), 2, pp. 129-137.

[6] Sanderson, S. W., Simons, K. L., Light emitting diodes and the lighting revolution: The emergence of a solid-state lighting industry, Research Policy, 43 (2014), 10, pp. 1730-1746.

[7] Wu, M., Huang, H., Huang, B., Tang, C., Cheng, C., Economic feasibility of solar-powered led roadway lighting, Renewable Energy,34 (2009), 8, pp. 1934-1938. 
[8] Xiaobing, L., Zhangming, M., Sheng, L., Thermal design of a 16W LED bulb based on thermal analysis of a $4 \mathrm{~W}$ LED bulb, Proceedings of IEEE, $60^{\text {th }}$ Electronic Components and Technology Conferance (ECTC 2010), Las Vegas, NV, USA, 2010.

[9] Vahaplar, K., Gürdal, A. Ö., Kesgin, G., Aydınlatmada LED ve LED Üretim Teknolojileri.

[10] Shur, M., Zukauskas, R.,Solid-State Lighting: Toward Superior Illumination, Proceedings of the IEEE, 2005, 93, pp. $1691-1703$.

[11] Maaspuro, M.,Tuominen, A., Thermal analysis of LED spot lighting device operating in external natural or forced heat convection,Microelectronics Reliability,53 (2013), 3, pp. 428-434.

[12] Weiming, L., QingLiang, Z., YuZhen, X., Qiang, Z.,Temperature effect on performance and reliability of QR tapped-inductor Buck LED driver, Proceedings, International Power Electronics and Application Conference and Exposition, Shanghai, China, 2014.

[13] Zhang, H., Developing highly reliable LED luminaires for high temperature applications using ACdirect driving LED technology, Proceeding, 2018 IEEE Applied Power Electronics Conference and Exposition (APEC), San Antonio, TX, USA, 2018.

[14] King, M., Thermal Management Basics and its Importance for LED Luminaire Performance and Cost, 2010

[15] Schutt, E., Thermal management and design optimization for a high-power LED work light,Plastics Technology, 2014.

[16] Yun, J., Shim, J.I., Shin, D.S., Current, voltage and temperature distribution modeling of lightemitting diodes based on electrical and thermal circuit analysis, Semiconductor Science and Technology,28 (2013), 8 .

[17] PCB - an Important Piece of Puzzle in the LED Thermal Management, ThomasNet News, 2017.

[18] M. Grujicic, C. Zhao, E. Dusel, The effect of thermal contact resistance on heat management in the electronic packaging, Applied Surface Science, 246 (2005), 1-3, pp. 290-302.

[19]Bridelux, LED’ler Üzerindeki Termal Etki ve Uygun Soğutucu Seçimi, Bridelux Yayınları, İstanbul, Türkiye, pp. 5-15, 2017.

[20]***,ANTRAK, https://antrak.org.tr/genel/so\%C4\%9Futucular/ 